\title{
Bilder från CSA:s första tid
}

Bildmaterialet har använts i enlighet med upphovsrättslagen $22 \S$ om citaträtt i vetenskaplig eller kritisk framställning.
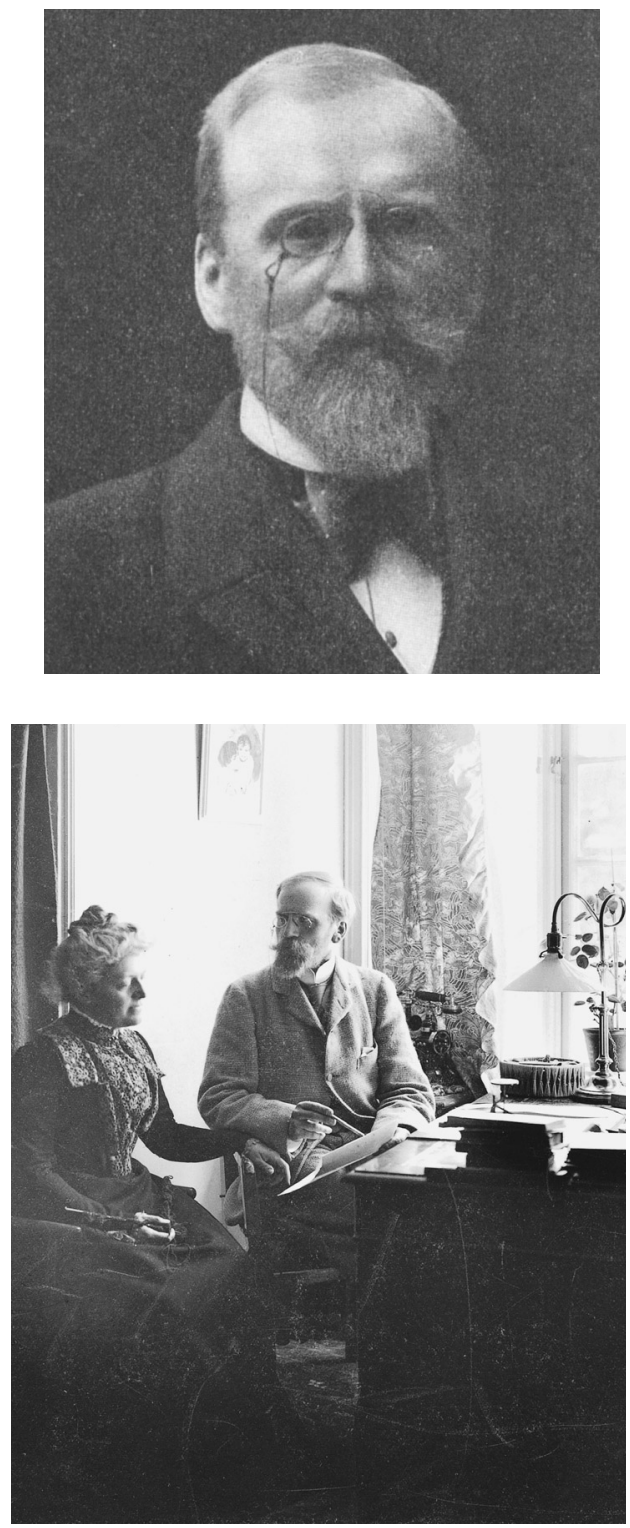

Ernst Beckman (kulturliberal riksdagsman) var CSA:s ordförande från starten 1903 till 1915. Bildkällor: Översta bilden från Social Tidskrift. Nedersta bilden från Stockholms stadsmuseum. 


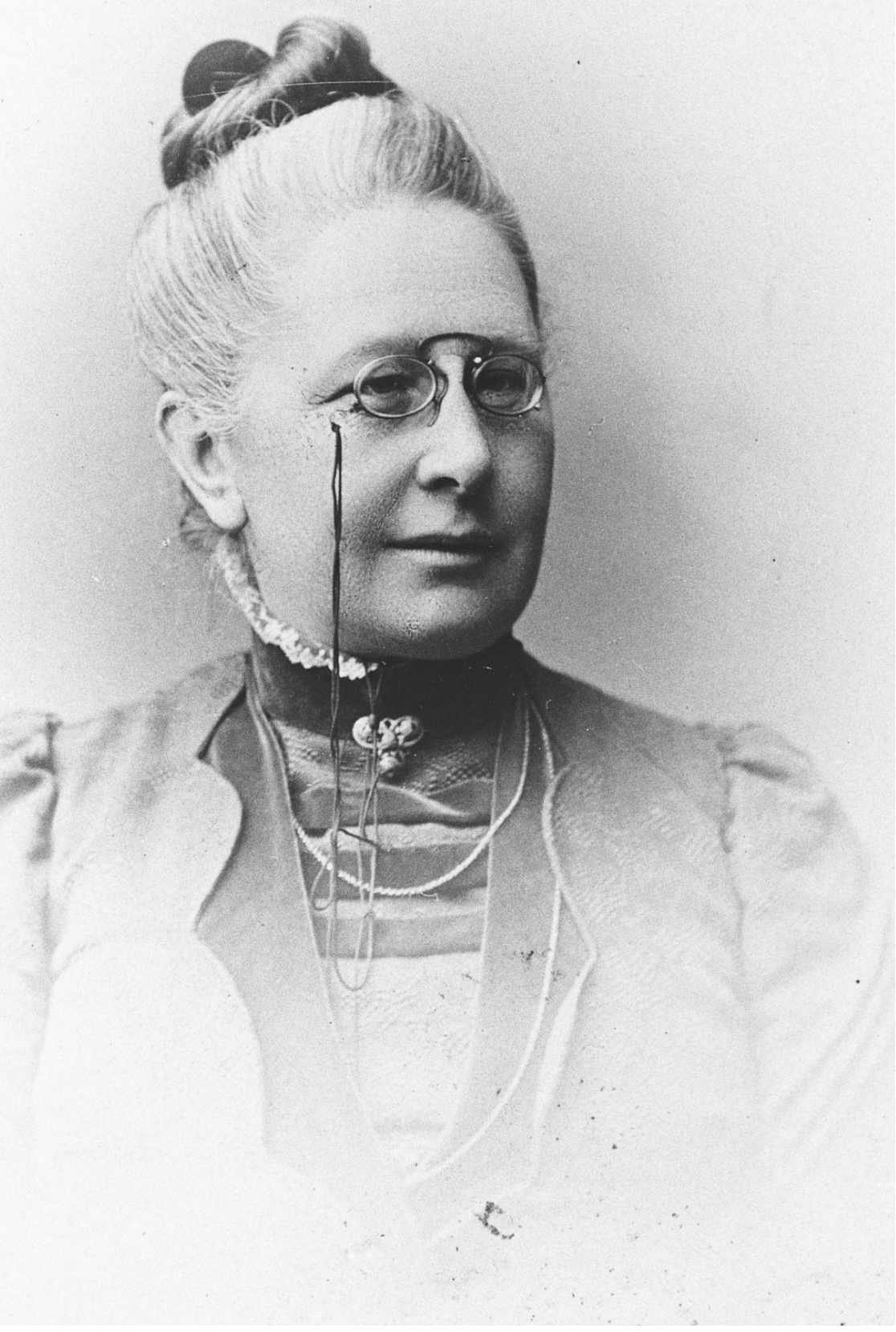

Agda Montelius (från Fredrika Bremerförbundet och Föreningen för Välgörenhetens Ordnande) var vice ordförande under åren 1903-1909.

Bildkälla: Arbetarrörelsens Arkiv och Bibliotek (von Kochs bildarkiv). 

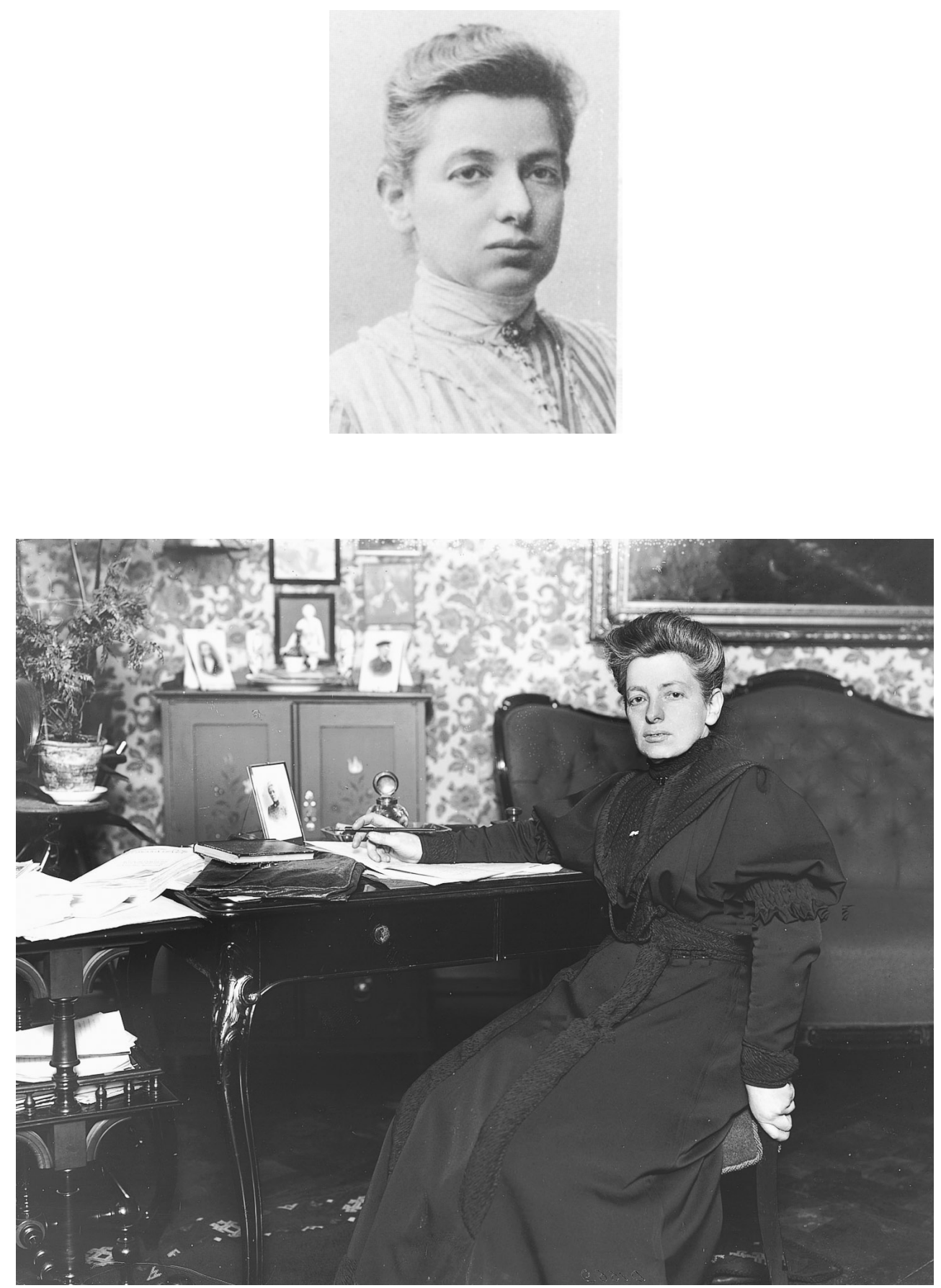

Gerda Meyerson (från föreningen Hem för arbeterskor) var sekreterare i förbundet 19031906 och styrelseledamot 1903-1921.

Bildkällor: Översta bilden från Social Tidskrift. Nedre bilden från Stockholms stadsmuseum. 

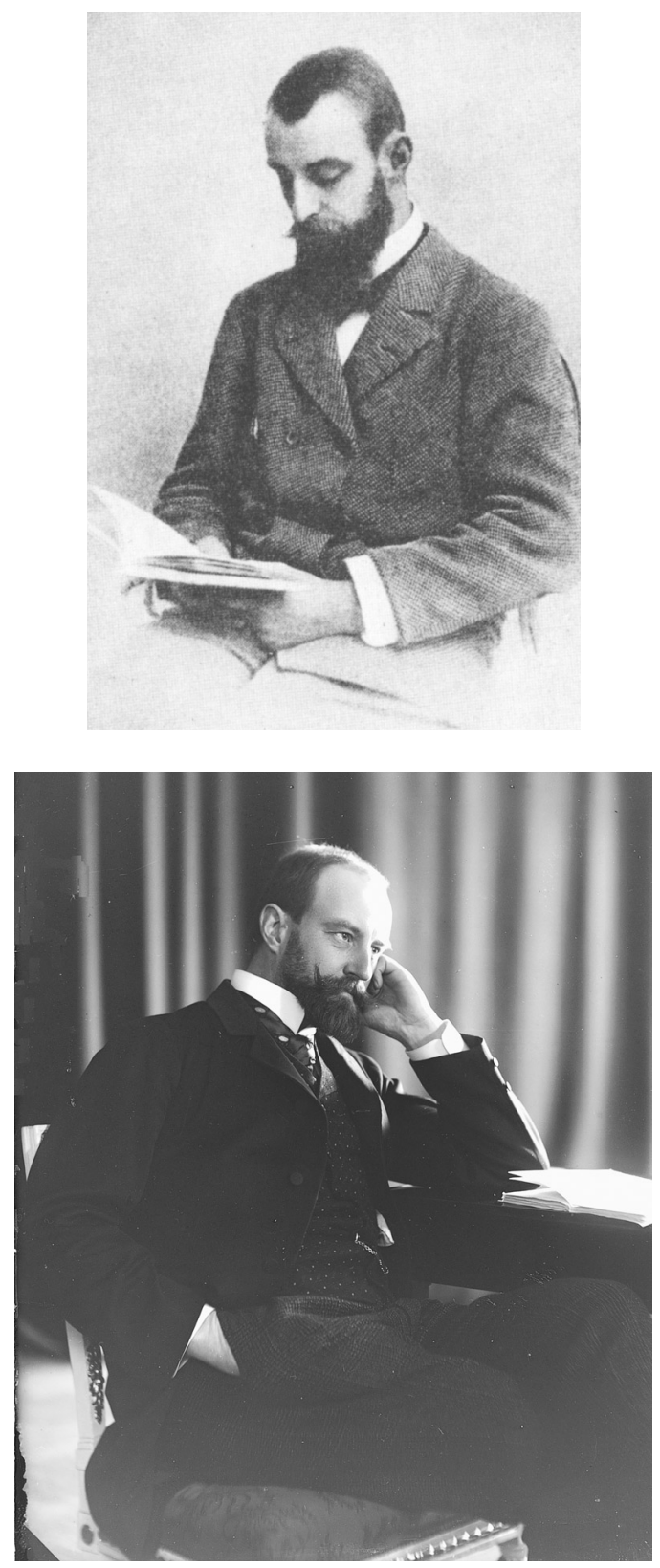

Gerhard Halfred von Koch (folkbildningsförbundet, sekreterare i KF, redaktör för Social Tidskrift) var styrelseledamot i CSA från 1903 fram till 1943. Under åren 1930-1940 var han ordförande i förbundet. Han var en av grundarna till Svenska Fattigvårdsförbundet och redaktör för Social Tidskrift 1901-1917.

Bildkällor: Översta bilden från Agnes Wirén G. H. von Koch, Banbrytare i Svensk socialvård(1980). Nedersta bilden från Stockholms stadsmuseum. 


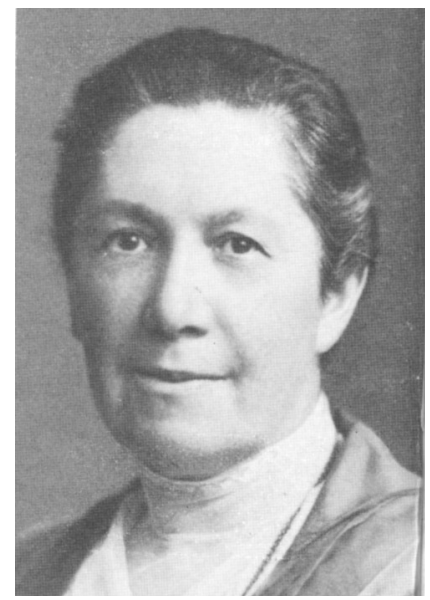

Emilia Broomé var byråföreståndare under åren 1904-1914.

Bildkälla: Agnes Wirén G. H. von Koch, Banbrytare i Svensk socialvård (1980).

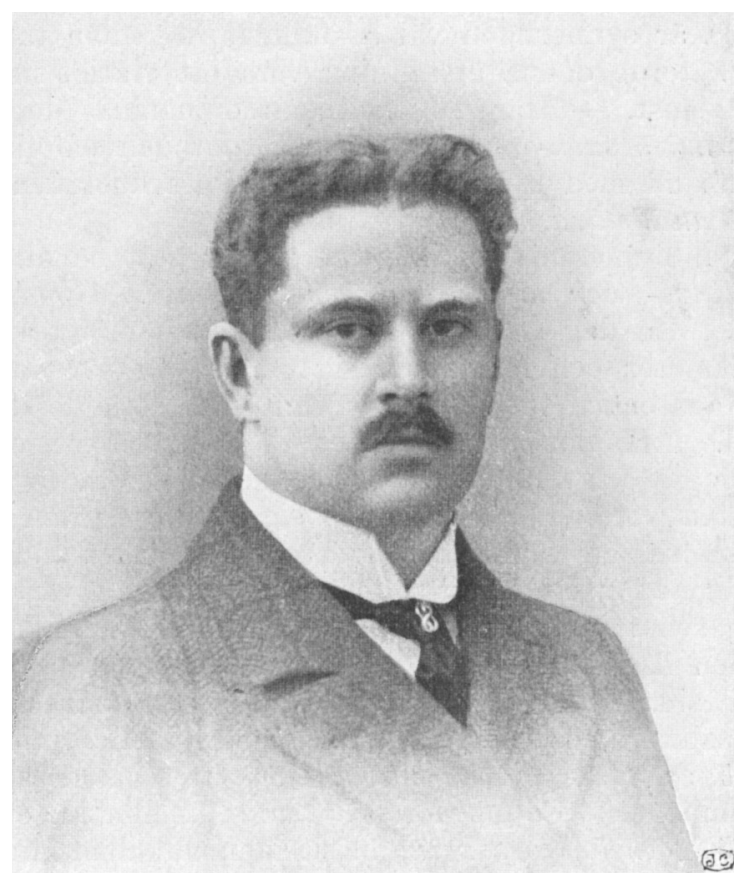

Erik Palmstierna (kapten, senare statsråd) var styrelseledamot 1906-1912 och sekreterare 1906-1908. Han medverkade aktivt med att anordna kongressen för Fattigvård och Folkförsäkring och var vid denna tid ledamot i stadsfullmäktige i Karlskrona. Han invaldes 1908 i andra kammaren som liberal men övergick 1910 till socialdemokraterna.

Bildkälla: Social Tidskrift. 


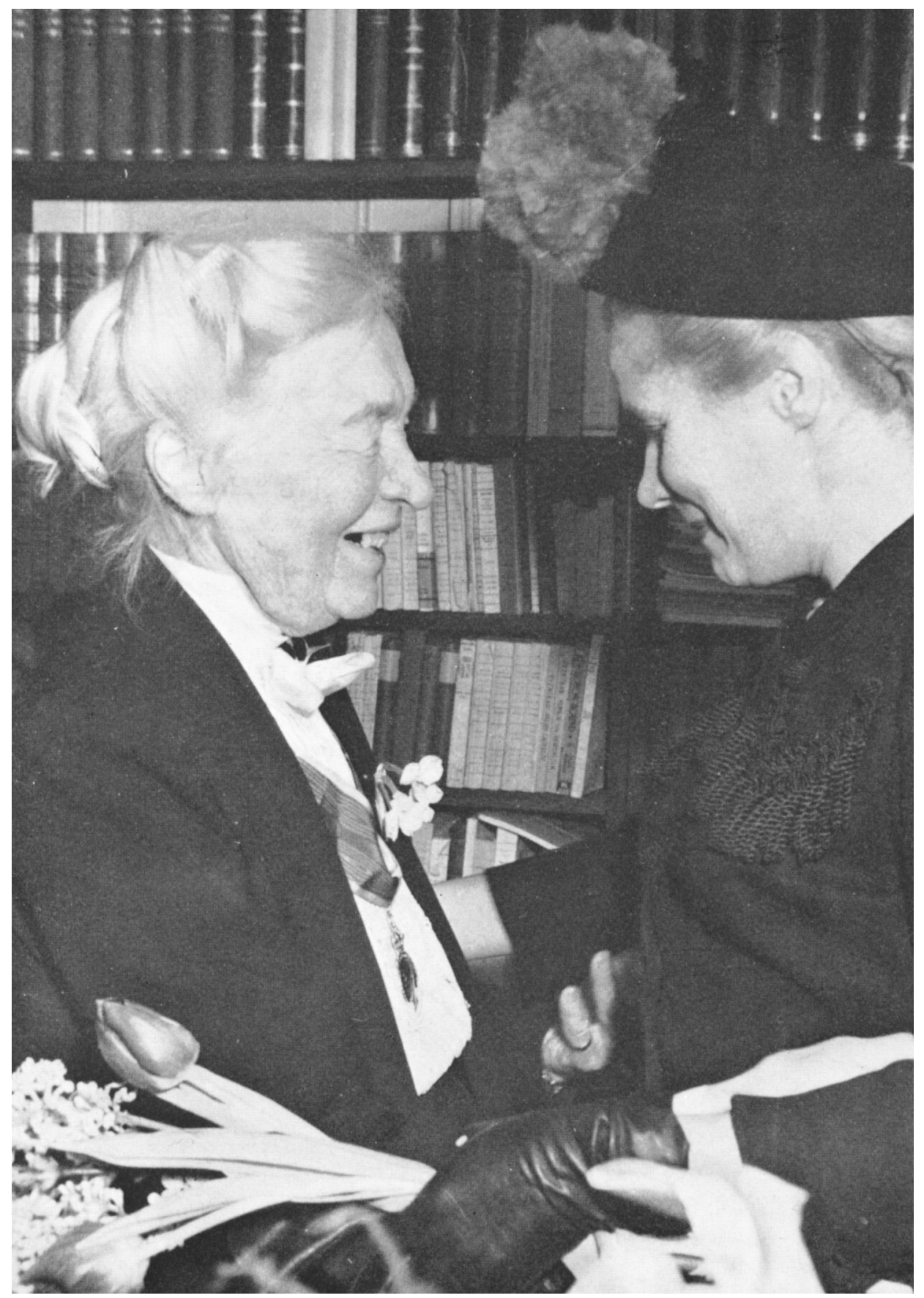

Kerstin Hesselgren (bostadsinspektör, senare riksdagsman) satt med i styrelsen 1906-1953 och var hedersmedlem 1953-1962. På bilden uppvaktas hon på sjuttiofemårsdagen av Alva Myrdal som var styrelseledamot i CSA 1944-1947. Bildkälla Rut Hamrin-Thorell, Ingrid Gärde Widemar, Alva Myrdal och Malin Bergman Boken om Kerstin Hesselgren(1968). 


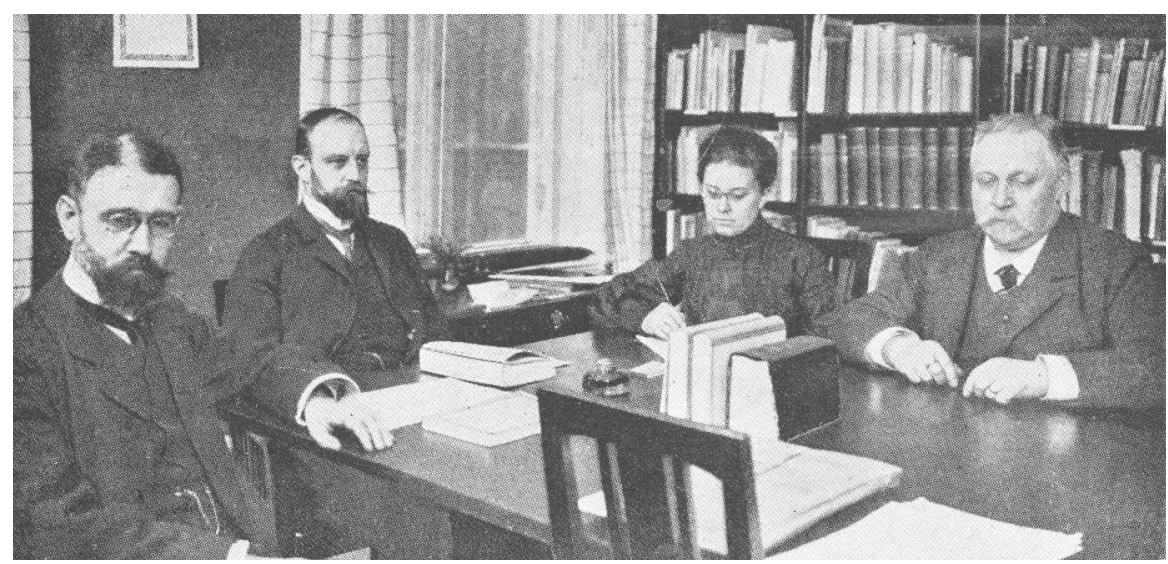

CSA:s fattigvårdskommitté. År 1904 fick CSA en gåva på 20000 kronor från en anonym givare som skulle användas till en allsidig utredning av fattigvårdsfrågan i in- och utlandet för att få till stånd en ny fattigvårdsförordning. Utredningen utfördes av en särskild kommitté bestående av fattigvårdsinspektören i Stockholm A. Lindblom, borgmästaren i Södertälje Jakob Pettersson, redaktören von Koch (ordförande) och Ebba Pauli (sekreterare). Kommittén arbetade under 2 år och publicerade resultatet i Reformlinjer för svensk fattiguairdslagstiftning.

Bildkälla: Agnes Wirén G. H. von Koch, Banbrytare i Svensk socialvård (1980). 


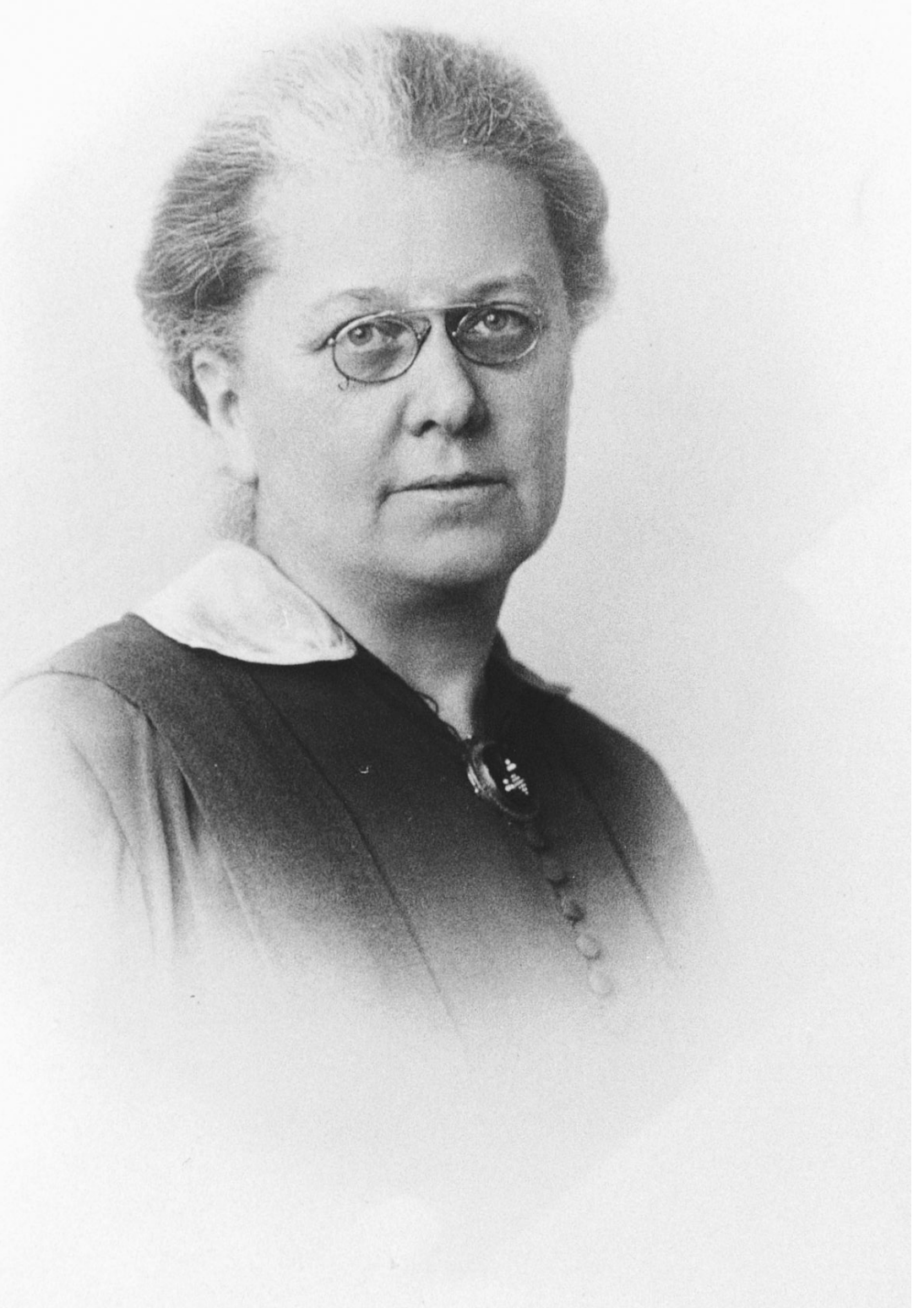

Ebba Pauli var sekreterare i CSA:s fattigvårdskommitté och var styrelseledamot i CSA 1929-1937.

Bildkälla: Arbetarrörelsens Arkiv och Bibliotek (von Kochs bildarkiv).

Socialvetenskaplig tidskrift nr 2-3・2003 


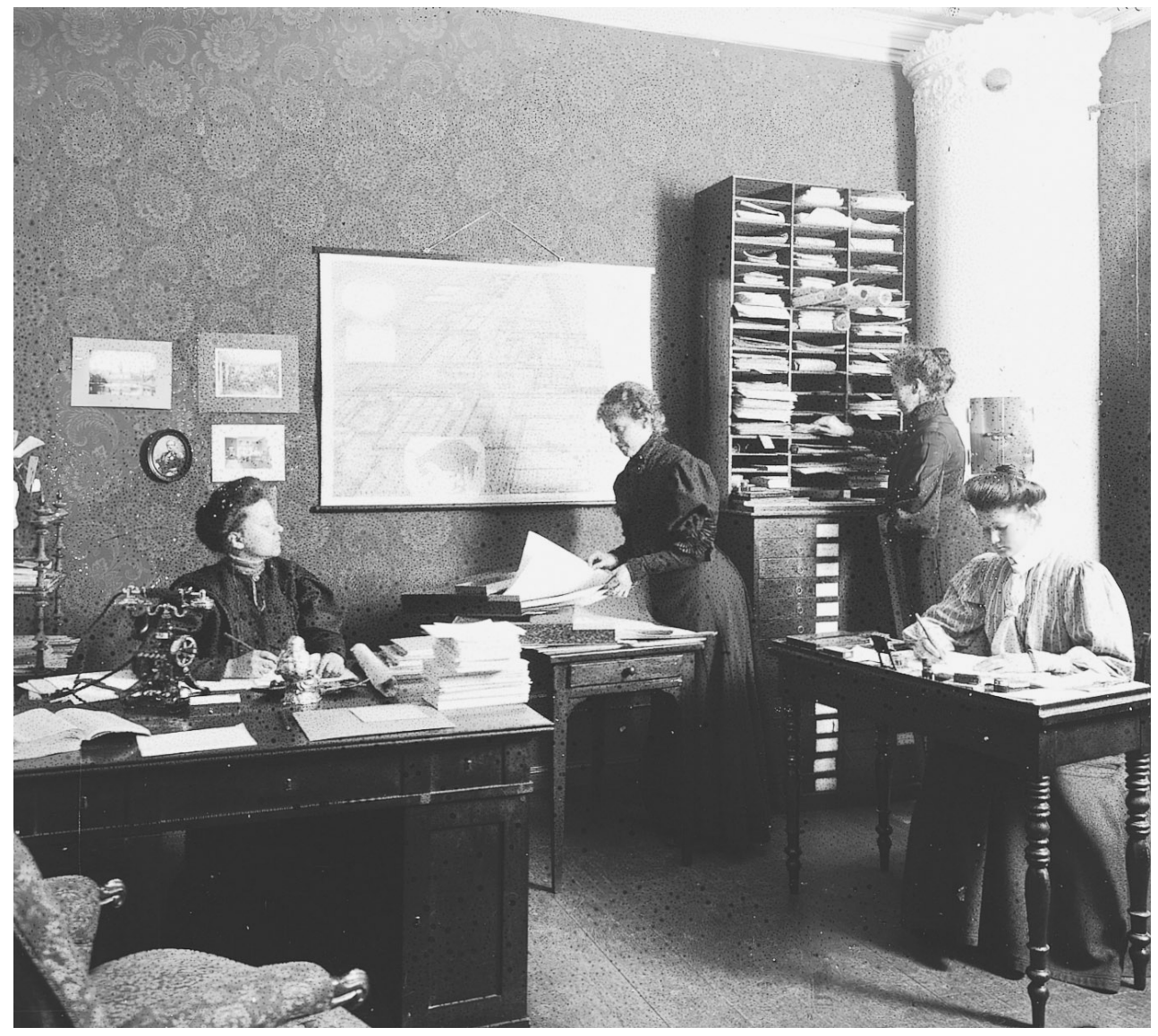

Praktiskt arbete i CSA:s fattigvårdskommitté på Lästmakaregatan 6 där CSA och Social Tidskrift från 1 oktober 1904 hade sina lokaler. Bildkälla: Stockholms stadsmuseum. 


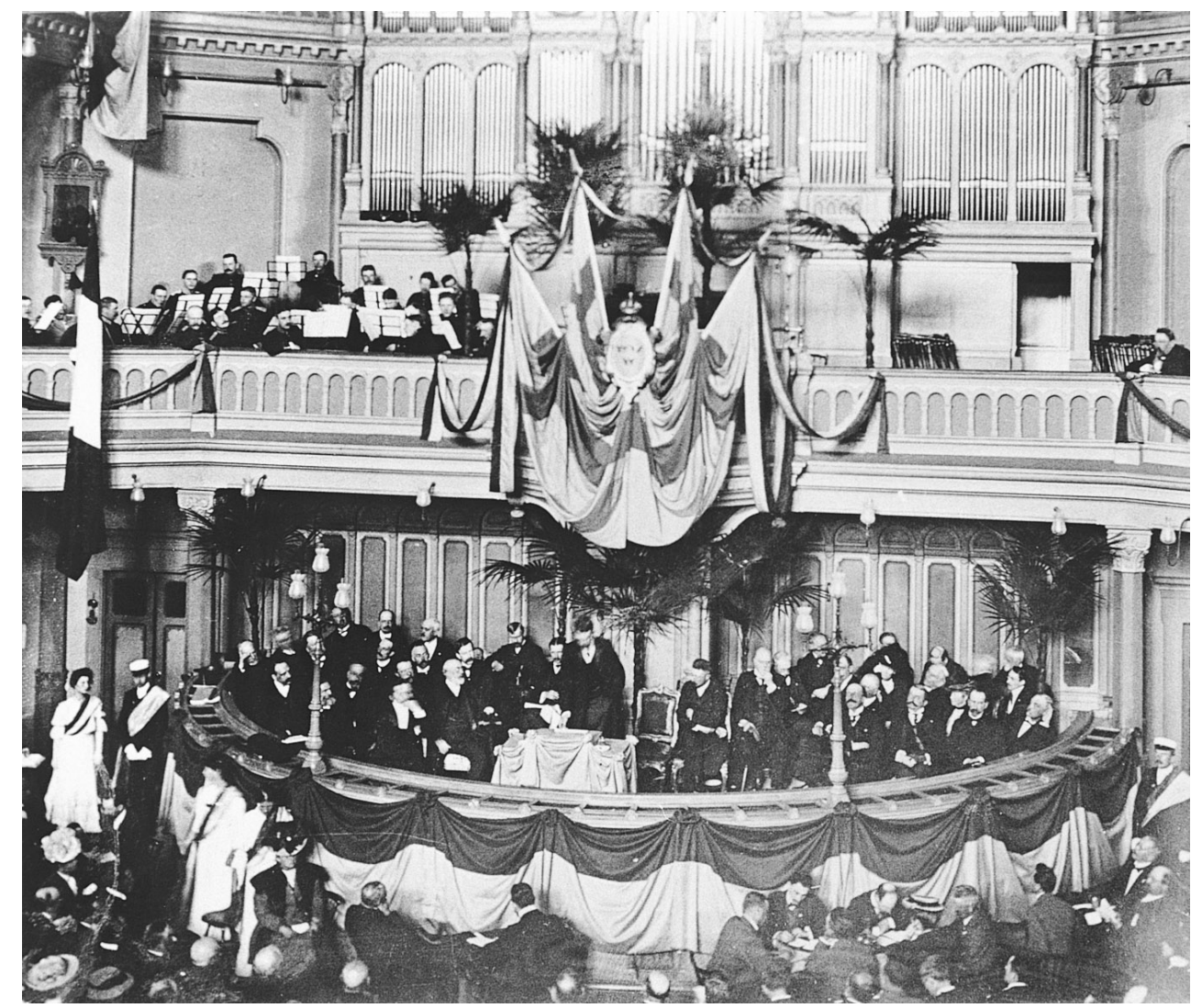

På fattigvårdskommitténs initiativ ordnade CSA Sveriges första stora social kongress med 936 deltagare. Den öppnades den 4 oktober 1906 i Blasieholmskyrkan i närvaro av medlemmar av kungahuset, regeringen och riksdagen.

Bildkälla: Arbetarrörelsens Arkiv och Bibliotek (von Kochs bildarkiv). 


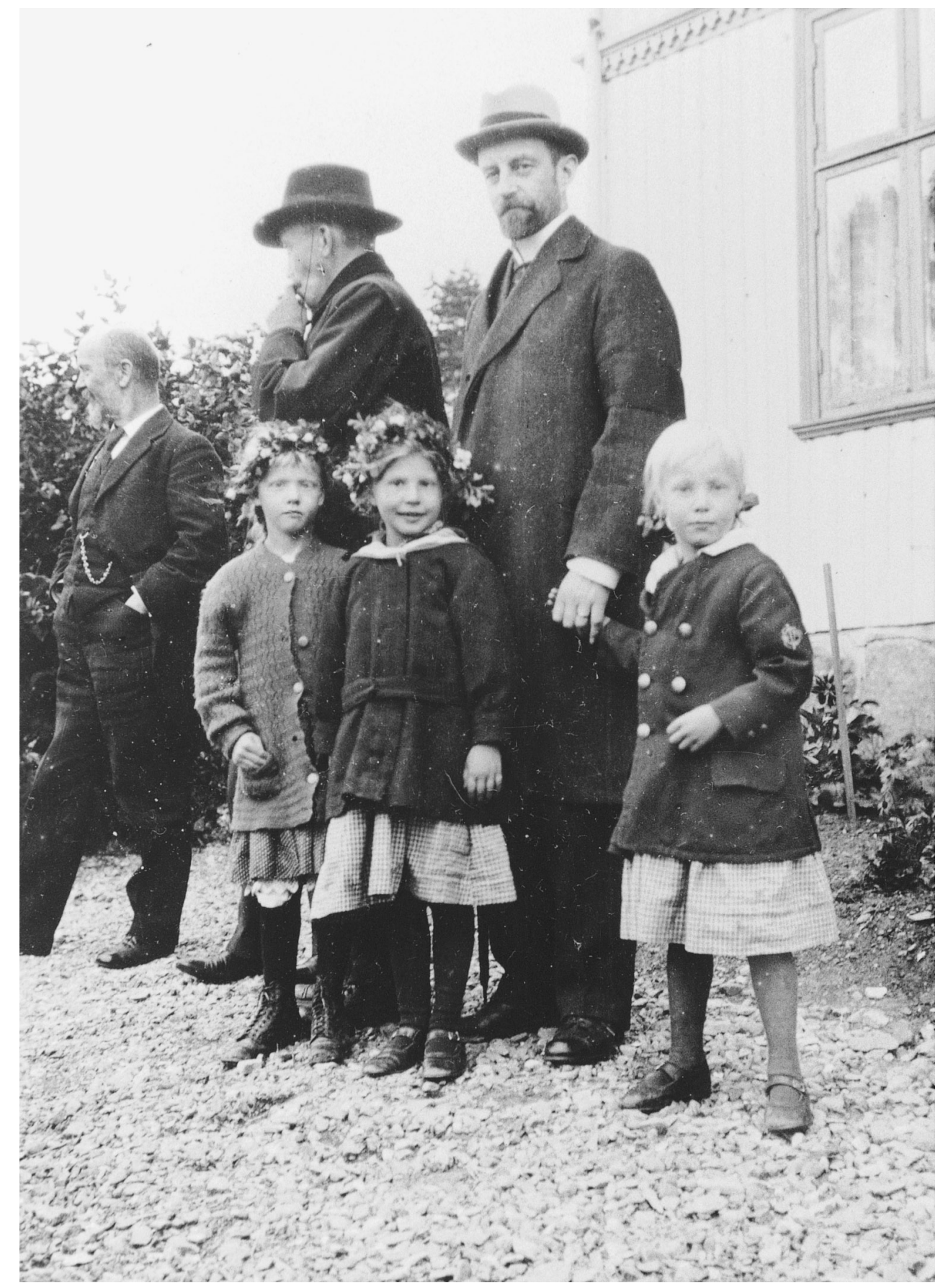

Representanter för CSA deltog i nationella, nordiska och internationella filantropmöten. Här en bild från svenska filantropmötet 1925 "G H von Koch och barnen".

Bildkälla: Arbetarrörelsens Arkiv och Bibliotek (von Kochs bildarkiv). 


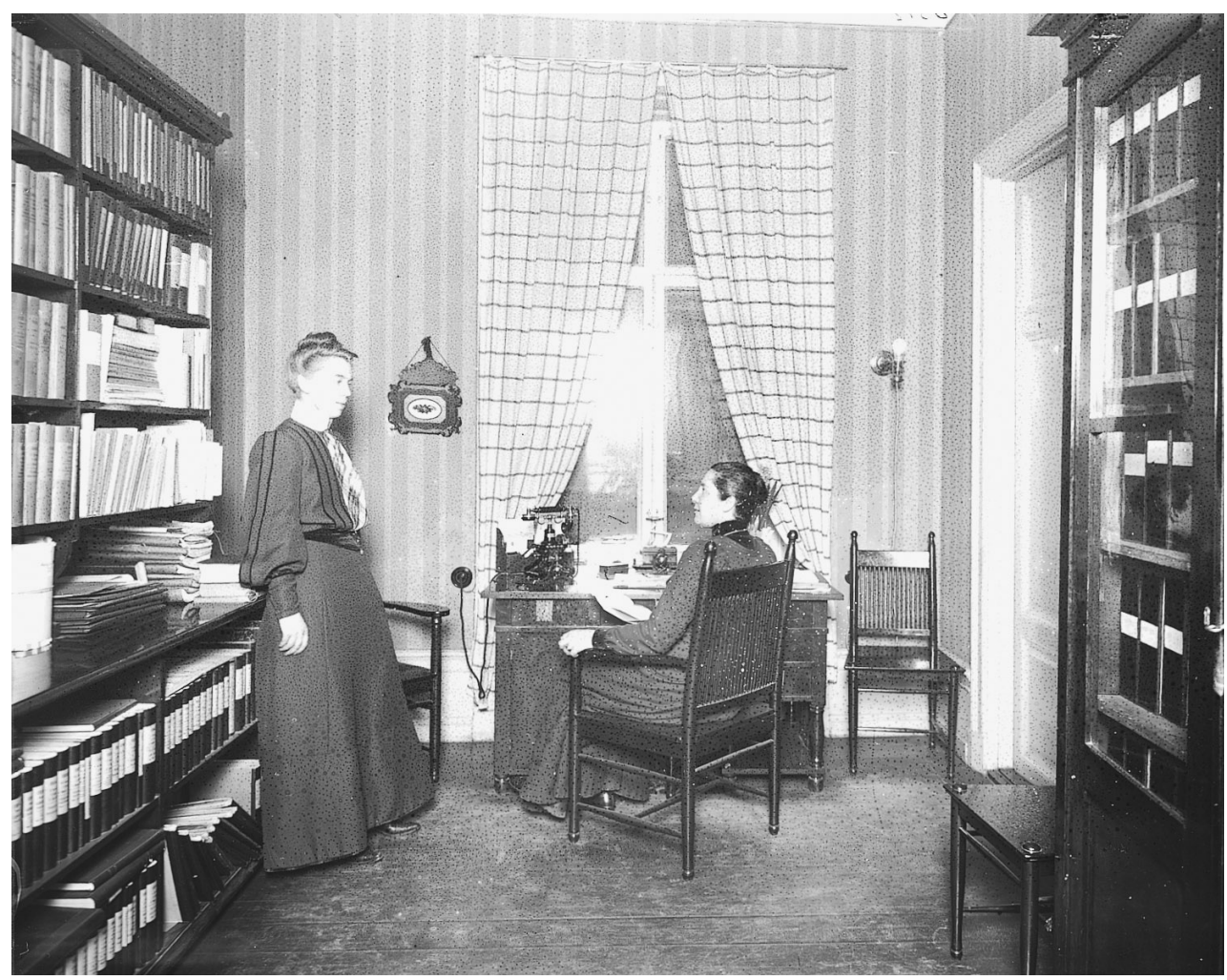

CSA:s upplysningsbyrå med föreståndarinnan Emilia Broomé. Bilden var publicerad i Idun $1906 \mathrm{i}$ en artikel om upplysningsbyrån med rubriken "Behöfva vi social kunskap?"

Bildkälla: Stockholms stadsmuseum. 


\section{Utbildningskurs}

för

\section{Praktiskt Socialt Arbete,}

såsom bostadsinspektion, vice värdskap i arbetarebostadshus, fosterbarnsinspektion och andra mera krävande uppgifter, anordnas under läsåret 1 Oktober 1912-1 Juli 1913 av

\section{Centralförbundet för Socialt Arbete.}

Elevantalet begränsat. Inträdesålder minst 21 år. Teoretisk och praktisk utbildning. Arsavgift $250 \mathrm{kr}$.

Fullständigt prospekt erhålles genom C. S. A:s byrå, Lästmakaregatan 6, Stockholm, där även anmälningar mottagas intill den 15 Juni.

Med detta häfte följer som bilaga en uppsats av professor C. G. Santesson: Materialism och vetenskap.

\section{SOEJAL TIDSKRJFT}

organ för Centralförbundet för Socialt Arbete. Redaktör: G. H. von Koch.

Pris: helt år kr. 5: 50, 1/2 år kr. 3:- Lösnummer 60 öre.

Prenumeration sker å posten, i bokhandeln eller å tidskriftens expedition.

Redaktion och expedition: 6 Lästmakaregatan, Stockholm, kl. 11-1 varje söckendag.

Distributör: Svenska Nykterhetsförlaget, Drottninggatan 55.

Stockholm. Oskar Eklunds boktryckeri, 1912.

Två annonser i Social Tidskrift. Tidskriften utgavs från 1901 som organ för Studenter och arbetare, men när CSA bildades blev den också dess organ. Från 1909 övertog förbundet tidningens utgivning och drev den fram till 1917 då den lades ner. Tidskriften anses under sina 17 år ha haft ett stort inflytande på det sociala reformarbetet. 


\section{Forsas minisymposium 2003}

\section{KUNSKAP, NYTTA OCH PRAKTIK PÅ HANDIKAPPOMRÅDET}

Symposiet vänder sig till alla med intresse för handikappfrågor, t.ex. brukare, yrkesverksamma i handikappomsorgen, socialtjänsten, politiker och tjänstemän, studenter, lärare och forskare. Symposiet arrangeras av: Forsa-Norr i samarbete med institutionen för socialt arbete, Umeå universitet och Centrum för handikappvetenskap vid Umeå universitet.

Var? Scandic hotell Plaza i Umeå (ODEON)

När? $\quad 18$ september 2003, kl. 13.00 - 16.30.

Pris? $\quad$ Symposiet är öppet för alla och kostnadsfritt.

Anmälan: $\quad$ För anmälan och information, skicka e-post till

Jens.Holmgren@socw.umu.se eller ring 090-7869878

13-13.10 Symposiets öppnande

13.10 - 13.30 Rafael Lindqvist, professor i socialt arbete och föreståndare för Centrum för handikappvetenskap vid Umeå universitet

13.30 - 14.30 Mårten Söder, professor i sociologi med inriktning mot handikapp.

14.30 - $15.00 \quad$ Kaffe och smörgås

15.00 - 15.20 Urban Markström, fil. Dr. institutionen för socialt arbete Umeå universitet

15.20 - 16.20 Paneldiskussion kring kunskapsutveckling på handikappområdet. I panelen: Rafael Lindqvist, Mårten Söder, representanter för brukarrörelsen, socialtjänsten i Umeå samt handikappförvaltningen, Landstinget.

16.20 - 16.30 Tapio Salonen, ordförande i FORSA, avslutar symposiet

17.00 - ca. 18.00 Årsmöte FORSA

Varmt välkomna till Umeå. 


\section{Vägledning till författarna}

Socialvetenskaplig Tidskrift publicerar artiklar, debattinlägg, bokrecensioner, presentationer av nya avhandlingar och andra nyheter inom forskningen.

Redaktionen välkomnar manuskript från alla områden inom forskningsfältet. Manuskripten skall vara skrivna på svenska.

Vetenskapliga artiklar bedöms av rådgivare med hög vetenskaplig kompetens inom olika specialområden.

Artiklarna skall vara teoretiska eller empiriska originalarbeten eller översiktsartiklar av något socialvetenskapligt intresseområde. Kommentarer och debattinlägg skall ta upp teoretiska och metodiska frågor, behandla kontroverser inom forskningsfältet, forskningspolitiska frågor m.m. Bokrecensioner och presentationer av avhandlingar trycks vanligen efter överenskommelse med redaktionen.

Manuskripten skall vara skrivna med dubbelt radavstånd och bred marginal. Artiklar skall inte överskrida 20 sidor (cirka 45000 tecken) inklusive noter, referenser m.m. Kommentarer och debattinlägg skall inte vara längre än 10 sidor och recensioner högst 5 sidor. Artiklarna skall innehålla en kort ingress och en kort engelsk sammanfattning. Artikelmanuskript sändes till redaktionen både per e-post och $\mathrm{i}$ tre pappersexemplar. När artikeln är bedömd skall författaren eventuellt bearbeta den och sända det slutliga manuskriptet till redaktionen dels per e-post, dels i ett pappersexemplar. Debattinlägg, kommentarer osv. insändes till redaktionen per e-post.

\section{Utformning av manuskript}

Nytt avsnitt markeras med indrag.

Noter anges med siffra och skrivs som fotnot.

Litteraturreferenser skrivs enligt följande:

1. I den löpande texten anges författarnamn, årtal och eventuella sidhänvisningar inom parantes i enlighet med följande exempel:

"...som Humphries (1984) visar", »flera forskare har dokumenterat detta (Gillis 1984, Mitterauer 1991).॥
2. Litteratur/referenslista placeras sist. Uppställning, indrag och kursivering sker som exemplen visar:

\section{Monografier}

Blos, Peter (1962) On Adolescence. A Psychoanalytic Interpretation. New York: The Free Press.

\section{Antologier/Artikelsamlingar}

Swärd, Hans (1990) „Reflexioner över några utvärderingars utgångspunkter». I Rosmarie Eliasson, Claes Levin, Anna Meeuwisse \& Sune Sunesson (red.) Den värderande blicken. Om utvärdering $i$ socialt arbete. Lund: Studentlitteratur.

\section{Tidskriftsartiklar}

Jeppsson Grassman, Eva (2001) »Tid, tillhörighet och anpassning." Socialvetenskaplig Tidskrift vol. $8 \mathrm{nr} 2$, s. 306- 325.

\section{Manuskripten skall innehålla följande:}
A. Titel och författarnamn
B. Kort sammandrag som ingress (ca 45 ord)
C. Själva texten
D. Numrerade noter vid behov (ange inte lit- teraturhänvisningar i noterna)
E. Litteraturreferenser, alfabetiskt ordnade
F. Engelsk sammanfattning (omkring 300 ord). Artikelns titel på engelska
G. Korta biografiska upplysningar om förfat- taren

Eventuella figurer skall vara tryckfärdiga.

Följ Svenska Skrivregler eller Myndigheternas skrivregler vid inskrivning av manuskripten, fra. vad gäller förkortningar.

I andra fall följ APA-normerna (APA Publication Manual Crib) http://www.wooster.edu/ psychology/apa-crib.html

Manuskript returneras vanligtvis inte. Redaktionen påtar sig inte heller ansvar för dem.

Artiklarna publiceras både i tidskriften och senare elektroniskt. 